\title{
Abnormal postprandial duodenal chyme transport in patients with long standing insulin dependent diabetes mellitus
}

\author{
H N Nguyen, J Silny, S Wüller, H-U Marschall, G Rau, S Matern
}

\begin{abstract}
Background-Patients with long standing diabetes mellitus frequently have upper gut dysmotility. Gastroparesis has been well studied, whereas detailed data on duodenal motor function are limited. Aims-To characterise postprandial duodenal chyme transport in such patients. Methods-Intraluminal multiple impedance measurement, recently introduced as a novel technique for investigation of chyme transport, was used to study postprandial duodenal chyme flow in 10 patients with long standing insulin dependent diabetes mellitus with gastroparesis, and 10 healthy volunteers. Results-Four distinct transport patterns of chyme, termed bolus transport events (BTEs), were found in both groups and could be characterised as: short distance propulsive; simple long distance propulsive; retrograde; and complex long distance propulsive. Diabetic patients had significantly lower numbers of propulsive BTEs $(p<0.01)$, and higher proportions of retrograde BTEs and complex long distance BTEs $(p<0.05)$ than control subjects, whereas the proportion of simple long distance BTEs was significantly lower $(p<0.05)$. The mean propagation velocities of the BTEs were similar in both groups. Conclusion-Abnormal postprandial duodenal chyme transport was found in patients with long standing insulin dependent diabetes mellitus. This is characterised by transport disorganisation and may result in disturbed chyme clearance. (Gut 1997; 41: 624-631)
\end{abstract}

Keywords: diabetic gastroparesis syndrome; postprandial chyme transport; intraluminal impedance measurement

In patients with long standing diabetes mellitus, upper gut motility dysfunction is a common phenomenon. ${ }^{1-3}$ Contributing factors include disease duration, history of poor glycaemic control, and signs of autonomic neuropathy. ${ }^{1}$ Diabetic gastroparesis is clinically the most significant condition; however, it is sometimes asymptomatic, probably due to visceral afferent neuropathy. ${ }^{4}$ Several abnormal motor mechanisms have been reported in relation to gastroparesis. ${ }^{5-7}$ Among the limited data concerning small intestine function, abnormal motor function ${ }^{3}$ and chyme transit ${ }^{8}{ }^{9}$ have been reported. Detailed studies of postprandial duodenal chyme flow have not been published however.

Recently, measurement of intraluminal multiple electrical impedance has been introduced as a novel technique with high resolution for the investigation of bolus transport phenomena. ${ }^{1011}$ This technique has been validated against other techniques for measurement of oesophageal and intestinal motility: in human oesophagus and small intestine, manometry and the impedance technique gave comparable parameters of motility, ${ }^{11-13}$ in human oesophagus simultaneous impedance and cineradiographic studies showed concordances of the bolus front movement, ${ }^{11}$ and compared with simultaneous pH-metry, the impedance technique detected not only acid but also non-acid gastrooesophageal reflux. ${ }^{14}$ In a previous study, ${ }^{15}$ we showed different chyme flow patterns in duodenum of healthy subjects during fasting and after a meal.

In the present study we prospectively selected a group of diabetic patients, in whom upper gut dysmotility was suspected from their medical history. Our major aim was to characterise postprandial chyme transport in these patients, applying the impedance technique.

\section{Materials and Methods}

MULTIPLE INTRALUMINAL ELECTRICAL IMPEDANCE PROCEDURE

The technique of multiple intraluminal measurement of electrical impedance was used to study bolus transport phenomena. Technical details have been published previously. ${ }^{1011} 15$ Briefly, the parameter measured is the change in luminal impedance $(Z)$ between electrodes during a bolus passage. The impedance depends inversely on the electrical conductivity of luminal contents and on the diameter of the lumen or bolus. As the electrical conductivity of gastric contents is higher than the conductivity of the muscular wall, bolus passage results in a drop in impedance at the corresponding measurement segments. Bolus passage can thus be distinguished from wall contractions since these cause an increase in impedance. ${ }^{10}{ }^{11}$

A custom made flexible polyvinyl catheter with a $2.6 \mathrm{~mm}$ outer diameter and $2.5 \mathrm{~m}$ long with 17 electrodes was used (standard assembly). The electrodes were $4 \mathrm{~mm}$ long, positioned $1.6 \mathrm{~cm}$ apart. Bipolar impedance measurements were performed between adjacent electrodes, yielding 16 recording segments
Accepted for publication 12 May 1997 
$2 \mathrm{~cm}$ long over a total distance of $32 \mathrm{~cm}$. In the validation studies with healthy subjects, instead of the standard assembly a combined catheter device was used in which the sixteenth and seventeenth electrodes were replaced by sensors measuring luminal $\mathrm{pH}$ and electrical conductivity, respectively. We thus used channels 1-14 for impedance, channel 15 for luminal $\mathrm{pH}$, and channel 16 for electrical conductivity measurements. This catheter device was applied to demonstrate that impedance patterns previously observed in healthy duodenum ${ }^{15}$ are associated with chyme passage, causing changes in luminal $\mathrm{pH}$ and conductivity.

Data acquisition was achieved by a mobile computer based system as previously described. ${ }^{12}$ After analogue to digital conversion, impedance signals were stored online on the hard disk of a personal computer with a sample frequency of $10 \mathrm{~Hz}$. Locally developed software was used for data acquisition, analysis, and graphics presentation.

\section{SUBJECTS}

Studies were performed in 10 patients with long standing insulin dependent diabetes mellitus, two patients with gastroparesis due to recurrent peptic ulcers, two patients with intestinal dysmotility due to progressive systemic sclerosis, and 14 healthy volunteers. None of the subjects had clinical evidence of biliopancreatic disease or previous cholecystectomy.

The diabetic patients (seven men and three women; mean age 38 years, range 23-48; mean disease duration 19 years, range 10-29) were selected from our diabetic outpatient clinic. Only patients who had recently been treated following an intensive insulin regimen with blood glucose self control and adjustable insulin doses were asked to participate in the studies, as this regimen would allow narrow control of postprandial glucose concentrations. Further selection criteria were: insulin dependent diabetes mellitus with disease duration greater than 10 years, history of poor glycaemic control, and previous evidence of gastroparesis. The latter was based either on prolonged gastric emptying time in previous scintigraphic examinations with a solid meal (egg white sandwich, sitting position, standardised routine investigation) or by the presence of gastric residue at endoscopy despite a 12 hour fast. Six patients had symptoms consistent with gastroparesis such as postprandial fullness and early satiety, but no patient complained of recurrent vomiting, diarrhoea, or constipation. Other diabetic complications were retinopathy $(n=4)$, nephropathy $(n=6)$, and peripheral neuropathy $(n=7)$. Gastric or duodenal obstruction was excluded by endoscopy, and intestinal obstruction was excluded by the patient's history. Regular medication which could affect gastrointestinal motility was discontinued at least one week before the examination.

Four other patients served as disease controls: two patients with gastroparesis due to recurrent peptic ulcers (60 year old man; 67 year old woman), diagnosed endoscopically with confirmation by barium meal; and two patients with intestinal dysmotility due to progressive systemic sclerosis ( 55 and 68 year old women), diagnosed by medical history with confirmation by manometry.

All healthy volunteers were tube naive and recruited from the medical staff. They took no medication and had no history of gastrointestinal disease. Ten subjects (seven men and three women; mean age 29 years, range $24-38$ years) served as control subjects for the diabetic patients. Four subjects (two men and two women; mean age 29 years, range $27-33$ years) participated in validation studies using the combined catheter device: two underwent fasting studies and the others postprandial studies.

Informed consent was obtained from each subject according to the Declaration of Helsinki. The study protocols had been approved by the local ethical committee of the University of Aachen.

\section{STUDY PROTOCOLS}

After an overnight fast from 2200 hours, the catheter was placed endoscopically into the duodenum, omitting medication affecting gastrointestinal motility. ${ }^{15}$ The proximal $1-4$ electrodes (1-3 channels) were positioned across the gastroduodenal junction, while the remaining electrodes were placed in the duodenum and the proximal jejunum. This catheter position yielded information about bolus transport from stomach into proximal duodenum (electrodes across the gastroduodenal junction), as well as bolus transport along the duodenum (electrodes along the duodenum). Final position was confirmed by fluoroscopy and controlled at the end of the measuring procedures. As our major aim was to study postprandial duodenal chyme transport, gastric emptying time was not assessed.

For all postprandial studies a standard test meal consisting of $500 \mathrm{~g}$ of commercially available yoghurt with small pieces of fruit (450 kcal, $400 \mathrm{ml}, 5.5 \mathrm{~g}$ fat, $12.5 \mathrm{~g}$ protein, $75 \mathrm{~g}$ carbohydrate) was administered after a resting period of at least 90 minutes following catheter placement. The test meal was chosen in accordance with a consensus from 1994, ${ }^{16}$ that the test meal volume should be 300$500 \mathrm{ml}$ and the total caloric load should be in excess of $300 \mathrm{kcal}$. The recording of impedance amplitudes was then started and continued for at least two hours. For fasting studies with the combined catheter device recording duration was four hours.

In the diabetic patients, capillary blood glucose was determined 30 minutes prior to the test meal, and 30 and 60 minutes after its administration using glucose test strips and a blood glucometer (Haemo-Glucotest and Reflolux S, Boehringer Mannheim, Mannheim, Germany). According to the preprandial blood glucose concentration an appropriate insulin dose was injected subcutaneously to maintain a blood glucose concentration of 6-10 $\mathrm{mmol} / \mathrm{l}$.

\section{DATA EVALUATION}

Impedance tracings were reconstructed onscreen and impedance patterns were analysed 


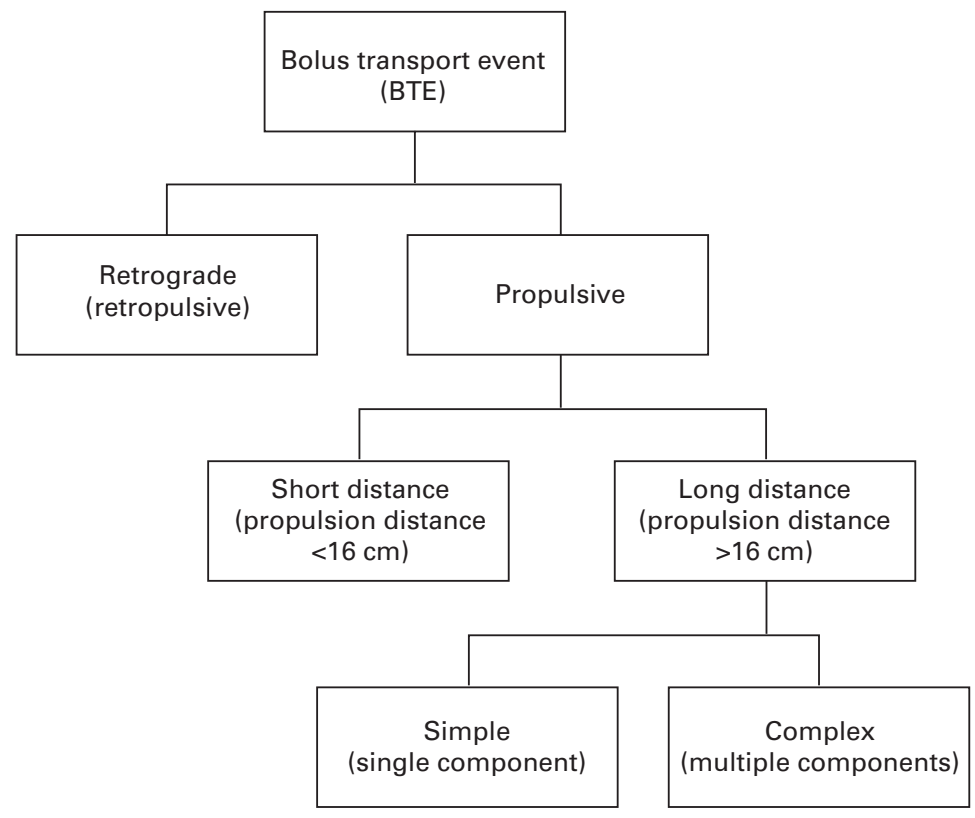

Figure 1: Classification algorithm for the bolus transport events.

A

|ZCh. Phase III

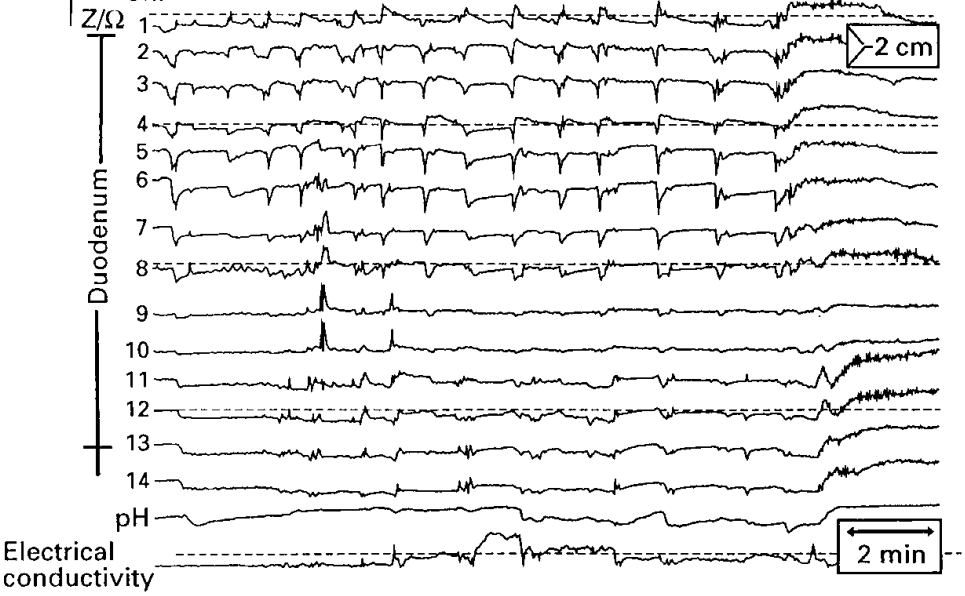

B

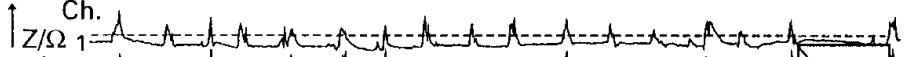
$+2 \mu r \lambda d r$

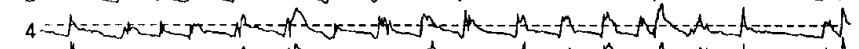

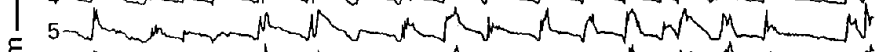

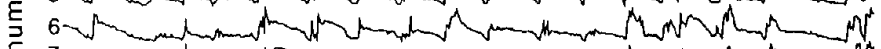

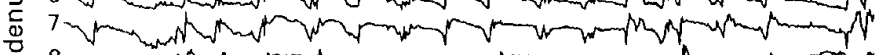

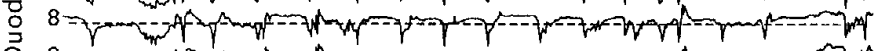

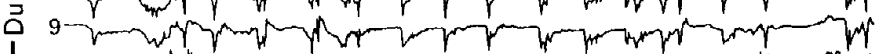

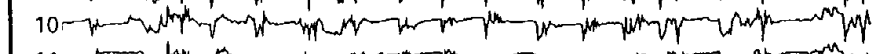
11 r wher

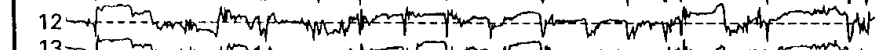
$T_{14-2}^{13-1}$ $\mathrm{PH}$

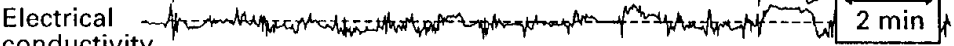
conductivity

Figure 2: Impedance tracings of two healthy subjects using a combined catheter device. Numbers and positions of measuring segments are shown at the left, channels 1-14, impedance; channel 15, luminal pH; channel 16, luminal electrical conductivity. (A) During the late phase II of a migrating motor complex cycle; (B) during the postprandial state. independently by two investigators ( $\mathrm{HN}$ and SW), one of whom had no knowledge of the subject studied. Only signals related to chyme transport over at least $6 \mathrm{~cm}$ were analysed and classified as bolus transport events (BTEs) as previously described. ${ }^{15}$ The term BTE is derived from studies in human oesophagus and represents typical impedance tracings related to transport of a bolus, recorded during bolus swallowing. ${ }^{11-13}$ Localised motor activities were not included. In this study, only propulsive BTEs originating from the antropyloroduodenal region were included. Based on the results of a previous study, ${ }^{15}$ the following classification algorithm was used (fig 1). Firstly, a BTE was classified as propulsive or retrograde according to the site of onset (proximal versus distal) and the propulsion direction (propulsive versus retropulsive). Secondly, propulsive BTEs were classified as short distance $(\leqslant 8$ channels) or long distance propulsive BTEs ( $>8$ channels or $16 \mathrm{~cm}$ ) according to the propulsion distances. Thirdly, long distance propulsive BTEs were classified as simple (one component) or complex long distance propulsive BTEs (multiple components) depending on the number of components. The BTEs were classified and quantified over a period of 90 minutes after completing the test meal. The average propagation velocities of the simple long distance propulsive BTEs along the duodenum were calculated from the migrating velocity of the so called "bolus mid point", seen from minimal impedance values in each segment.

DATA ANALYSIS

All values are expressed as median (range); BTEs were counted over 90 minutes. The Mann-Whitney rank sum test and linear regression analysis were used for statistical data comparisons; $\mathrm{p}<0.05$ was considered statistically significant.

\section{Results}

The mean haemoglobin $(\mathrm{Hb}) \mathrm{A}_{1 \mathrm{c}}$ value of the patients was $10.8 \%$ (range $6.7-14.7 \%$ ). Mean blood glucose concentrations were $9.7 \mathrm{mmol} / 1$ (range 7.2-13.2 $\mathrm{mmol} / \mathrm{l}$ ) 30 minutes before the test meal, and $10.6 \mathrm{mmol} / 1(8.5-11.2 \mathrm{mmol} / \mathrm{l})$ and $8.9 \mathrm{mmol} / 1(7.6-10.8 \mathrm{mmol} / \mathrm{l}), 30$ and 60 minutes later, respectively. All subjects tolerated the procedures well, and no complications occurred. Catheter migration of a maximum of three segments was observed in six subjects (four controls and two diabetics) at the end of the measuring procedures. However, since the total measuring length of $32 \mathrm{~cm}$ exceeds the length of the duodenum $(20-24 \mathrm{~cm})$, the duodenum was fully monitored in all cases.

In healthy subjects, both the interdigestive and the postprandial states were characterised by the frequent occurrence of BTEs, as shown in fig 2. BTEs which propagated beyond the duodenum were associated with changes in luminal electrical conductivity and $\mathrm{pH}$, indicating that chyme had passed the corresponding measuring segments. The results demonstrated that impedance tracings related to a BTE are associated with chyme transport. 
CHARACTERISTICS OF POSTPRANDIAL DUODENAL CHYME TRANSPORT

No phase III activity of the migrating motor complex (MMC) cycle was seen during the evaluation period of 90 minutes after completing the test meal in all normal subjects. In contrast, tracings of two diabetics showed phase III activities at 82 and 85 minutes, respectively.

The postprandial impedance patterns obtained from diabetic patients (fig 3A) differed from those obtained from healthy subjects (fig 3B) and from patients with other causes of upper gut dysmotility (figs 3C and 3D). Diabetic patients had a notably reduced number of BTEs compared with healthy subjects. The predominant transport pattern in the patient with gastroparesis due to recurrent peptic ulcers was short distance propulsive BTE (fig 3C). Few signals related to regular chyme transport were seen in the patient with intestinal dysmotility due to progressive systemic sclerosis (fig 3D). Note in figs $3 \mathrm{~A}-\mathrm{C}$ that there were several BTEs which originated from the antropyloroduodenal region and propagated along the duodenum into the jejunum. Each such BTE indicates a bolus transport from the stomach into the duodenum. Tracings of the diabetic patient (A) and the patient with gastroparesis (C) featured a notably lower frequency of BTEs as compared with the healthy subject (B), indicating a lower gastric emptying frequency in these patients. A major proportion of BTEs in the patient with gastroparesis (C) was short distance propulsive. Tracings of the patient with progressive systemic sclerosis (D) featured only signs of irregular chyme transport.

Both in diabetic patients and control subjects, four chyme transport patterns have been characterised during the postprandial phase: short distance propulsive; simple long distance propulsive; retrograde; or complex long distance propulsive BTE, as shown in fig 4. (Short distance, propulsion distance $\leqslant 16 \mathrm{~cm}$ or eight segments; long distance, propulsion distance $>16 \mathrm{~cm}$ or eight segments; simple, one component; complex, multiple components.) Using the classification algorithms shown in fig 1, all complex and retrograde BTEs were clearly identified. There was a discordance rate of about $5 \%$ between the two observers as to whether a simple propulsive BTE was to be classified as short distance or long distance. In such cases the mean was used for quantitative determination of BTEs.

Table 1 shows the mean incidences of the BTEs over 90 minutes after completing the meal and their contributions; significant
A

Ch.

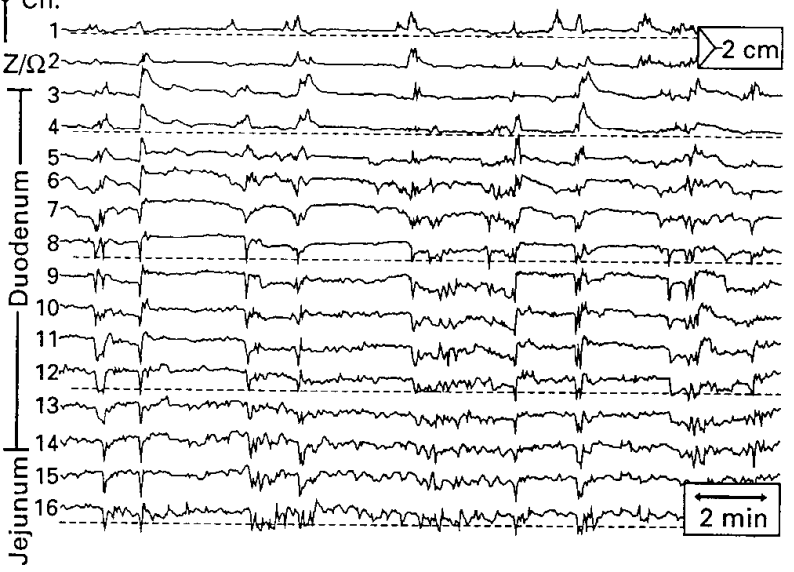

C

Ch.

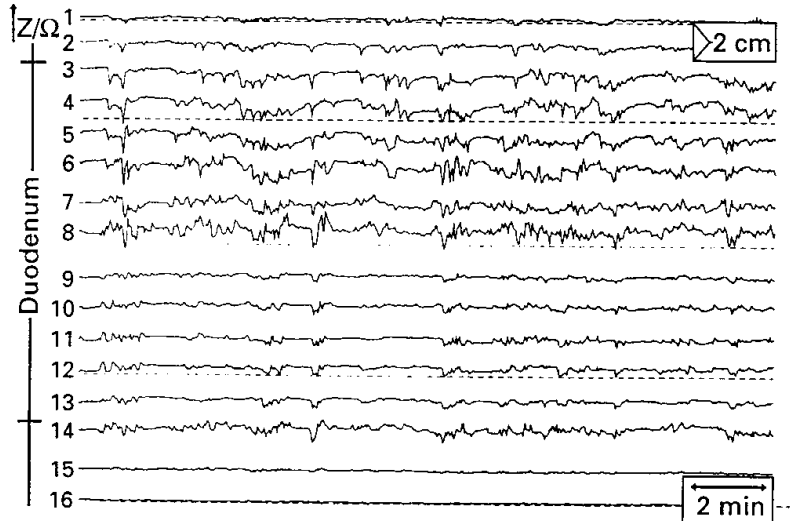

B

$\left.\right|_{Z / \Omega} \mathrm{Ch}$.

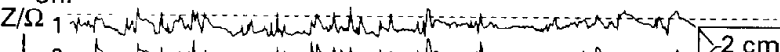

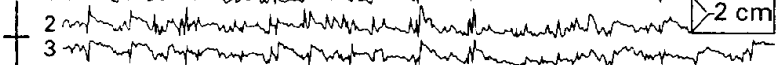

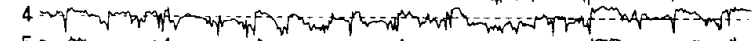

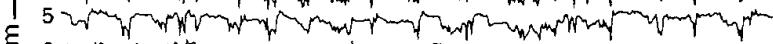

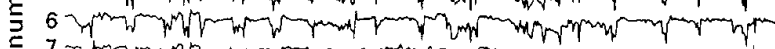

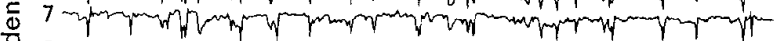

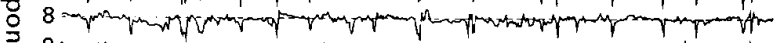

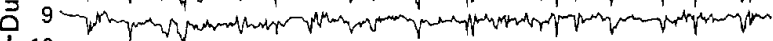

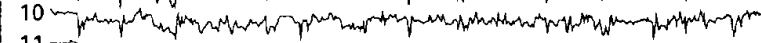

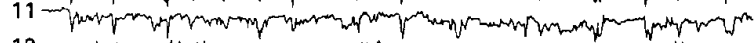

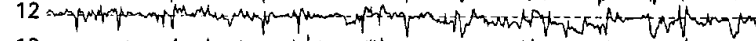

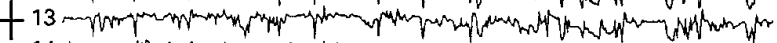

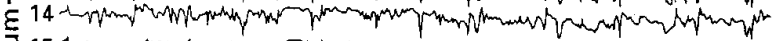

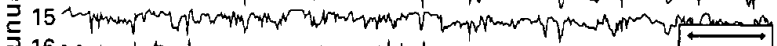

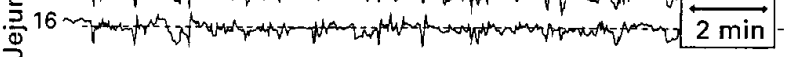

D

Ch.

$Z / \Omega 2$ - 1 -

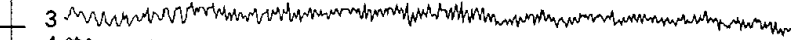
4 M.

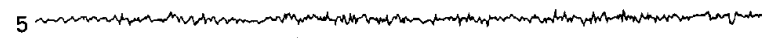

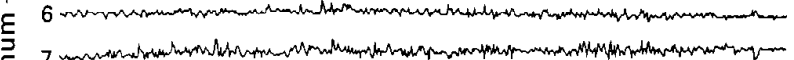

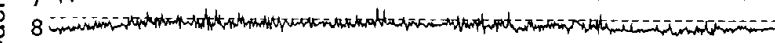

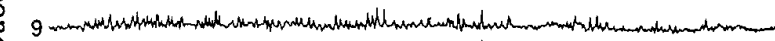

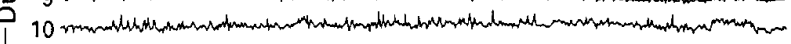
11 intum

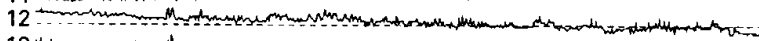

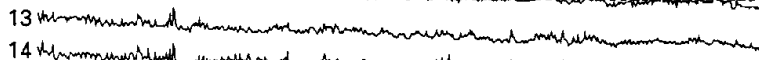

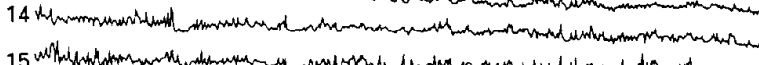

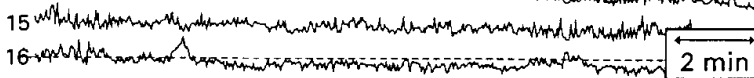

Figure 3: Examples of postprandial impedance tracings, 10 minutes after the test meal using the standard catheter device. Numbers and positions of measuring segments are shown at the left. (A) Diabetic patient (30 year old man); (B) healthy subject (26 year old man); (C) patient with gastroparesis due to recurrent peptic ulcers (60 year old man); (D) patient with intestinal dysmotility due to progressive systemic sclerosis (55 year old woman). 
TABLE 1 Numbers of the different classes of bolus transport events (BTEs) determined during 90 minutes after the test meal. Data are given as median (range) and per cent (range)

\begin{tabular}{llllll}
\hline & $\begin{array}{l}\text { Short distance } \\
\text { propulsive BTEs }\end{array}$ & $\begin{array}{l}\text { Simple long distance } \\
\text { propulsive BTEs }\end{array}$ & $\begin{array}{l}\text { Complex long distance } \\
\text { propulsive BTEs }\end{array}$ & Retrograde BTEs & $\begin{array}{l}\text { Total number of } \\
\text { BTEs }\end{array}$ \\
\hline $\begin{array}{l}\text { Diabetic patients } \\
(\mathrm{n}=10)\end{array}$ & $12^{\star}(8-21)$ & $52.5^{\star}(32-78)$ & $7.5(4-12)$ & $9.5(6-15)$ & $80.5^{\star}(57-108)$ \\
& $1 \%^{\star}(11-2)$ & $62 \%^{\star}(55-71)$ & $8 \%^{\star}(5-14)$ & $13 \%^{\star}(8-19)$ & $100 \%$ \\
$\begin{array}{l}\text { Control subjects } \\
(\mathrm{n}=10)\end{array}$ & $24(11-31)$ & $84(60-112)$ & $5.5(4-10)$ & $7(6-10)$ & $117(91-160)$ \\
& $18 \%(5-24)$ & $70 \%(61-81)$ & $5 \%(3-7)$ & $7 \%(4-10)$ & $100 \%$ \\
\hline
\end{tabular}

${ }^{\star} \mathrm{p}<0.05 v$ control subjects.

differences between both groups are evident. The numbers of short distance and simple long distance propulsive BTEs were significantly lower in diabetic patients than in control subjects, whereas the numbers of other BTEs were higher. We found significantly higher frequencies of retrograde BTEs and complex BTEs in the diabetic patients compared with control subjects, whereas the frequency of simple BTEs was significantly lower. Within each group there was no significant correlation, as estimated by linear regression analysis, between the age of subjects and the number of each type of BTE.

According to the classification algorithm of BTEs, the following ratios (quotients) were calculated as parameters for the organisation of duodenal chyme transport: retrograde BTEs to propulsive BTEs; complex long distance BTEs to simple long distance BTEs; and short distance BTEs to long distance BTEs. Diabetic patients had a significantly higher ratio of retrograde to propulsive BTEs (0.129 (range $0.087-0.242$ ) versus 0.065

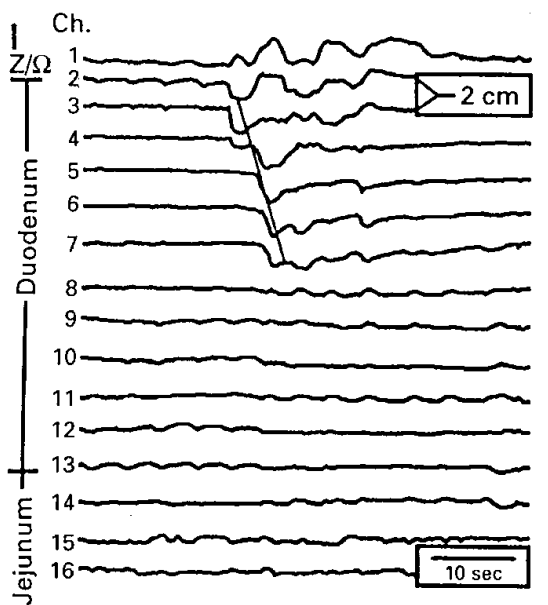

Short distance propulsive BTE

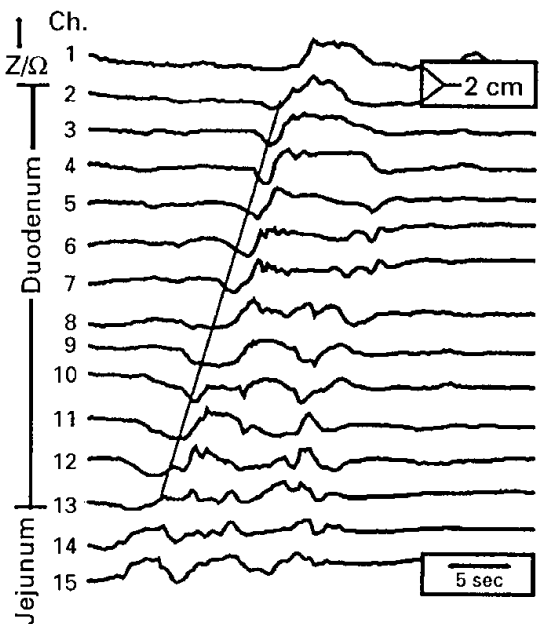

Retrograde BTE

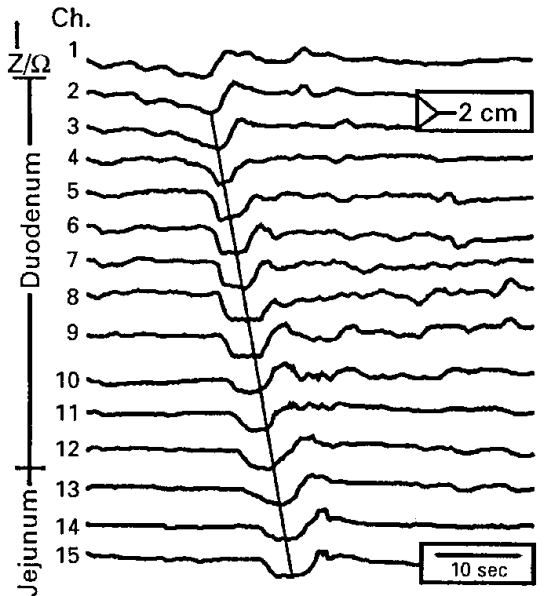

Simple long distance propulsive BTE

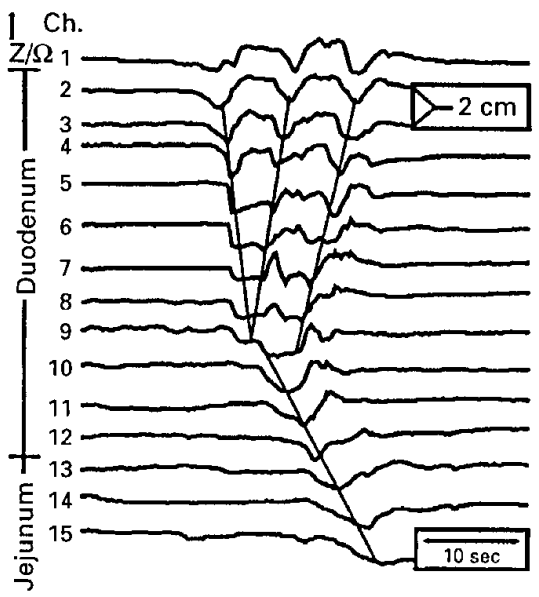

Complex long distance propulsive BTE

Figure 4: Examples of the main BTEs, observed postprandially. The numbers (maximum 16) and positions of the measuring segments in duodenum or jejunum are shown at the left margin. Top left panel, short distance propulsive BTE originating from proximal duodenum; top right panel, a simple long distance propulsive BTE starting from proximal duodenum; bottom left panel, a retrograde BTE starting from proximal jejunum; bottom right panel, a complex long distance propulsive BTE featuring one long distance propulsive component with two additional retrograde components starting from mid-duodenum during bolus propulsion. 

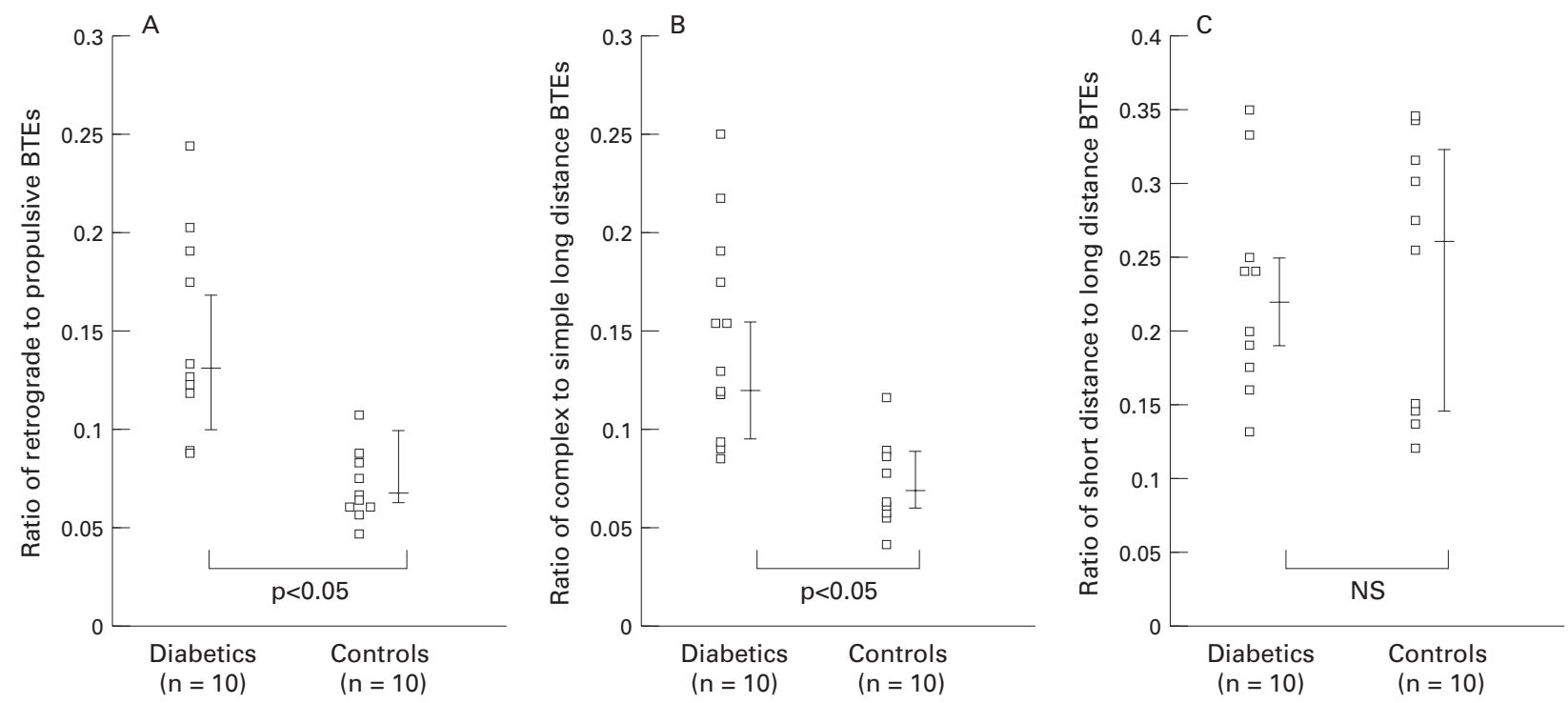

Figure 5: Ratios of the different classes of BTE in diabetic patients compared with healthy controls. Bars are median and interquartile range.

(range 0.046-0.106), $\mathrm{p}<0.05$ ) than control subjects, as shown in fig $5 \mathrm{~A}$. The same result was obtained for the ratio of complex long distance to simple long distance BTEs (0.124 (range 0.086-0.250) versus 0.065 (range $0.042-0.117$ ), $\mathrm{p}<0.05$ ) (fig 5B). The ratios of short distance propulsive to long distance propulsive BTEs were similar in both groups (0.220 (range 0.133-0.350) in diabetic patients versus 0.264 (range $0.121-0.345$ ) in control subjects) (fig 5C). The average propulsion velocities of the bolus along the duodenum were similar in both groups (1.7 (range $0.4-7.8$ ) in diabetics versus 1.5 (range 0.4 $8.0) \mathrm{cm} / \mathrm{sec}$ in healthy subjects).

\section{Discussion}

Gastroduodenal motor dysfunction is a frequent complication of long standing diabetes mellitus. Although gastroparesis has been well investigated, detailed data on postprandial duodenal chyme transport are limited because of methodological difficulties. Using the novel technique of multiple intraluminal electrical impedance measurement, we characterised postprandial chyme transport in patients with long standing diabetes mellitus and compared the results with those in control subjects. Both groups featured the same chyme transport patterns, termed BTEs: short distance propulsive; simple long distance propulsive; retrograde; and complex long distance propulsive. However, detailed analyses revealed significant differences in numbers and contributions of the BTEs between both groups.

The main transport pattern in both groups was long distance propulsive, indicating that a major proportion of gastric contents is rapidly transported into the proximal jejunum. It is possible that short distance propulsive BTEs represent the effects of gastric "pumping" with a common cavity transmitting force through an open pylorus. In contrast, long distance propulsive BTEs seemed to be associated with propagated duodenal contractions, and their propulsion velocities were similar at the proxi- mal and distal duodenum..$^{15}$ These results indicate that additional effort of the duodenum supports the propulsion of a bolus into the jejunum. Using a special assembly, Ahluwalia et $a l^{17}$ demonstrated that during phases II and III of the interdisgestive state and after a meal the duodenum is able to generate aboral traction forces. These results seem to be in contrast to previous work done by Weems and Seygal ${ }^{18}$ who studied the ability to propel fluid in isolated perfused intestinal segments using a non-nutrient test meal, namely a modified Krebs solution. They found that in contrast to the ileal segments, segments of the proximal duodenum failed to produce net propulsion of luminal contents. Under these experimental conditions the duodenum seems to be a conduit rather than a propulsive segment of intestine. However, their results are not comparable with the results of our current studies, because the experimental designs were quite different. Firstly, the test meals currently used were calorie rich. Secondly, the present study was performed in vivo, where chyme entering the duodenum has a different $\mathrm{pH}$, oncotic pressure, and nutrient content to the modified Krebs solution in vitro. It has been shown previously that the characteristics of the luminal contents entering the duodenum significantly influence duodenal motility activity. ${ }^{19-21}$

Diabetic patients had a significantly lower number of propulsive BTEs than control subjects. According to the position of the electrodes and the definition of the BTEs, these results implicate a reduced number of bolus passages across the gastroduodenal junction, indicating a reduced gastric emptying frequency in these patients, consistent with gastroparesis. This is in agreement with a significantly lower number of coordinated antropyloroduodenal and propagated duodenal pressure waves as previously demonstrated using manometry. ${ }^{7}$ As impaired antral motor function has previously been reported in diabetics, ${ }^{35}$ further studies are required to determine the relation between antral motor 
function and propulsive duodenal chyme transport activity.

In addition, diabetic patients showed a significantly higher proportion of retrograde BTEs and complex BTEs (table 1), or higher ratios of retrograde BTEs to propulsive BTEs and complex long distance BTEs to simple long distance propulsive BTEs, respectively (figs $5 \mathrm{~A}$ and $5 \mathrm{~B}$ ), than did control subjects. These data thus show abnormal postprandial duodenal chyme transport in the diabetic patients as a part of the upper gut dysmotility. These abnormalities, however, seem to be different from those found in patients with gastroparesis due to mechanical obstruction or with intestinal motor dysfunction due to progressive systemic sclerosis (figs $3 \mathrm{C}$ and 3D). Thus, we do not consider the abnormal duodenal chyme transport to be caused by gastroparesis. The results, however, extend information about postprandial duodenal motor function in diabetic patients.

In a previous study, ${ }^{15}$ we showed that the predominant transport pattern during fasting was short distance propulsive, but long distance propulsive after the meal. Complex long distance propulsive BTEs were found to be restricted to the postprandial state. Thus, the chyme transport patterns seem to depend on the nutritional state and on the amount of chyme entering the duodenum: large chyme amounts (postprandial) are reflected by long distance (simple or complex) propulsive BTEs, whereas small chyme amounts (fasting) are reflected by short distance BTEs. According to their classification, short distance propulsive BTEs were considered to be associated with propulsive chyme transport within the duodenum, whereas simple long distance propulsive BTEs were associated with propulsive chyme transport from the stomach into the jejunum. Retrograde BTEs were associated with chyme transport from the jejunum back into the duodenum. Complex long distance propulsive BTEs consist of multiple components and seem to represent mixed flow patterns associated with stirring and mixing chyme during its propulsion. Thus, the higher ratios of retrograde BTEs to propulsive BTEs and complex long distance BTEs to simple long distance propulsive BTEs in the diabetic patients implicate disturbed propulsive chyme transport through the duodenum. Chyme transport from stomach into jejunum may be delayed, or the duodenal chyme clearance activity decreased. These findings are in agreement with previous studies showing delayed intestinal chyme transit in diabetics. ${ }^{89}$ However, the similar propulsion velocities of propulsive BTEs in both groups imply that the duodenum of diabetic patients is not paretic. Therefore, we prefer the term duodenal chyme transport disorganisation to describe our findings.

Gastroduodenal dysmotility in diabetic patients was previously considered to be mainly due to vagal damage and autonomic neuropathy. ${ }^{1}$ Recent studies implied that hyperglycaemia disturbs gastroduodenal motility as this condition slows gastric emptying ${ }^{22}$ by inhibition of antral contractions and stimula- tion of localised pyloric contractions. ${ }^{23}$ Gastric myoelectrical disturbances in diabetic patients, especially tachygastrias, but not dysrhythmias, as registered by surface electrogastrography, are significantly influenced by blood glucose concentrations. ${ }^{24}{ }^{25}$ In these studies, the blood glucose concentrations were 16-20, 12-16, and $15-17 \mathrm{mmol} / \mathrm{l}$, respectively. ${ }^{22} 23$ Studying mechanisms of accelerated gastric emptying of liquids and hyperglycaemia in patients with non-insulin dependent diabetes mellitus, Frank et $a l^{26}$ found that excessive hepatic glucose release, but not rapid entry of ingested glucose, is the primary cause of postprandial hyperglycaemia in these patients. Although our patients were administered appropriate insulin doses prior to the test meal to keep postprandial blood glucose concentrations below $12 \mathrm{mmol} / \mathrm{l}$, we cannot exclude this effect on postprandial duodenal chyme transport. Effects of hyperglycaemia on small intestinal motor activity should be elucidated in further studies.

Since mechanisms related to gastroparesis are complex and not fully understood, ${ }^{7}$ the pathophysiological meaning of postprandial duodenal chyme transport disorganisation merits further elucidation. Gastroparesis was shown to be associated with antral hypomotility, ${ }^{5}$ pyloric dysmotility, ${ }^{6}$ or abnormal antroduodenal contractions. ${ }^{7}$ Gastric emptying can also be modulated by postpyloric mechanisms: intraduodenal nutrient perfusion may inhibit gastric emptying via neurohormonal feedback mechanisms, ${ }^{20}{ }_{2127-29}$ and nonpropagating duodenal contractions may provide mechanical resistance to gastric emptying. ${ }^{30}$ Gastric stasis on the other hand was shown to be partially associated with abnormal proximal intestinal motility. ${ }^{31} \mathrm{~A}$ recently published study underlined the role of the duodenum as an immediate brake to gastric outflow. ${ }^{32}$ Thus, the contribution of postprandial duodenal chyme transport disorganisation, as one postpyloric mechanism causing delayed gastric emptying, remains to be defined. This will help in the understanding of the heterogeneity of the gastroparesis syndrome ${ }^{7}$ and the different effects of putative gastroprokinetic agents on gastric emptying..$^{33} 34$

In conclusion, abnormal postprandial duodenal chyme transport is frequently found in patients with long standing insulin dependent diabetes mellitus. It seems to be a part of the gastroparesis syndrome and is characterised by disorganisation of chyme transport along the duodenum. It may result in impaired duodenal chyme clearance.

This paper is dedicated to Professor Dr H C W Gerok on the occasion of his 70th birthday. The authors thank Mr G Laven for his skillful technical assistance during recording sessions. Preliminary data were presented in part at the 15th International Symposium on Gastrointestinal Motility, Rome, Italy, 5-9 November 1995, and published in abstract form (Neurogastroenterol Mot 1995; 7: 277).

1 Feldmann M, Schiller LR. Disorders of gastrointestinal motility associated with diabetes mellitus. Ann Intern Med 1983; 98: $378-84$

2 Horowitz M, Harding PE, Maddox A, Maddern GJ, Collins PJ, Chatterton BE, et al. Gastric and oesophageal emptying in insulin dependent diabetes mellitus. $f$ Gastroenterol Hepatol 1986; 1: 97-113. 
3 Camilleri M, Malagelada JR. Abnormal intestinal motility in diabetics with the gastroparesis syndrome. Eur $\mathcal{F}$ Clin Invest diabetics with the

4 Rathmann W, Enck P, Frieling T, Gries FA. Visceral afferent neuropathy in diabetic gastroparesis. Diabetes Care 1991; 14: $1086-9$

5 Malagelada JR, Rees WD, Mazzotta LJ, Go VLW. Gastric motor abnormalities in diabetic and postvagotomy gastroparesis: effect of metoclopramide and betanechol. Gastroenterology 1980; 78: 286-93.

6 Mearin F, Camilleri M, Malagelada JR. Pyloric dysfunction in diabetics with recurrent nausea and vomiting. Gastroenterology 1986; 90: 1919-25.

7 Fraser R, Horowitz M, Maddox A, Dent J. Organization of antral, pyloric and duodenal motility in patients with
gastroparesis. Neurogastroenterol Mot 1993; 5: 167-75.

8 Scarpello JH, Greaves M, Sladen GE. Small intestinal transit in diabetics. BMF 1976; 2 : 1225-6.

9 Spengler U, Stellaard F, Ruckdeschel G, Scheurlen C, Kruis W. Small intestinal transit, bacterial growth, and bowel W. Small intestinal transit, bacterial growth, and

10 Silny J. Intraluminal multiple electric impedance procedure for measurement of gastrointestinal motility. Neurogastroenterol Mot 1991; 3: 151-62.

11 Silny J, Knigge KP, Fass J, Rau G, Matern S, Schumpelick V. Verification of the intraluminal multiple electrical impedance measurement for the recording of gastrointestinal motility. Neurogastroenterol Mot 1993; 5: 107-22.

12 Fass J, Silny J, Braun J, Heindrichs U, Dreuw B, Schumpelick V, Rau G. Measuring esophageal motility with a new intraluminal impedance device. First clinical results in reflux patients. Scand 7 Gastroenterol 1994; 29: 693-702.

13 Frieling T, Hermann S, Kuhlbusch R, Enck P, Silny J, Lübke HJ, et al. Comparison between intraluminal multiple electric impedance measurement and manometry in the human oesophagus. Neurogastroenterol Mot 1996; 8: 45-50.

14 Skopnik H, Silny J, Heiber O, Schulz J, Rau G, Heimann G. Gastroesophageal reflux in infants: evaluation of a new Gastroesophageal reflux in infants: evaluation of a new 23: $591-8$.

15 Nguyen HN, Silny J, Wüller S, Marschall HU, Rau G, Matern S. Chyme transport patterns in human duodenum determined by multiple intraluminal impedancometry. $A m$ 7 Physiol 1995; 268: G700-8.

16 Smout AJP, Horowitz M, Armstrong D. Methods to study gastric emptying. Dig Dis Sci 1994; 39: 130S-2S

17 Ahluwalia NK, Thompson DG, Barlow J, Heggie L. Human small intestinal contractions and aboral traction forces during fasting and after feeding. Gut 1994; 35: 625-30.

18 Weems WA, Seygal GE. Fluid propulsion by cat intestinal segments under conditions requiring hydrostatic work. $A m$ f Physiol 1981; 240: G147-56.

19 Thompson DG, Wingate DL. Effects of osmoreceptor stimulation on human duodenal motor activity. Gut 1988 29: $173-80$.
20 Heddle R, Collins PJ, Dent J, Horowitz M, Read NW, Chatterton B, Houghton LA. Motor mechanism associated with slowing of gastric emptying of a solid meal by an intraduodenal lipid infusion. F Gastroenterol Hepatol 1989; 4: 437-47.

21 Heddle R, Dent J, Read NW, Houghton LA, Toouli L, Horowitz $\mathrm{M}$, et al. Antropyloroduodenal motor responses to intraduodenal lipid infusion in healthy volunteers. $A m \mathcal{F}$ Physiol 1988; 254: G671-9.

22 Fraser R, Horowitz M, Maddox AF, Harding PE, Chartterton BE, Dent J. Hyperglycaemia slows gastric emptying in 1990 1 (insulin-dep 33: 675-80.

23 Fraser R, Horowitz M, Dent J. Hyperglycaemia stimulates pyloric motility in normal subjects. Gut 1991; 31: 475-8.

24 Jebbink HJ, Bruijs PP, Bravenboer B, Akkermanns LM, vanBerge-Henegouwen GP, Smout AJ. Gastric myoelectrical activity in patients with type I diabetes mellitus and autonomic neuropathy. Dig Dis Sci 1994; 39: 2376-83.

25 Jebbink HJ, Samsom M, Bruijs PP, Bravenboer B, Akkermanns LM, vanBerge-Henegouwen GP, Smout AJ. Hyperglycemia induces abnormalities of gastric myoelecHyperglycemia induces abnormalities of gastric myoelectrical activity in patients with type

26 Frank JW, Saslow SB, Camilleri M, Thomforde GM, Dinneen S, Rizza RA. Mechanism of accelerated gastric emptying of liquids and hyperglycemia in patients with type II diabetes mellitus. Gastroenterology 1995; 109: 755-65.

27 Meeroff JC, Go VLW, Phillips SF. Control of gastric emptying by osmolality of duodenal contents in man. Gastroenterology $1975 ; 68$ : $1144-51$.

28 Cooke AR, Clark ED. Effects of first part of duodenum on gastric emptying in dogs: response to acid, fat, glucose and neural blockade. Gastroenterology 1976; 70: 550-5.

29 Prather CM, Camilleri M, Thomforde GM, Forstrom LA, Zinsmeister AR. Gastric axial forces in experimentally delayed and accelerated gastric emptying. Am $f$ Physiol 1993; 264: G928-34.

30 Haba T, Sarna SK. Regulation of gastroduodenal emptying of solids by gastropyloroduodenal contractions. $\mathrm{Am} \mathcal{f}$ Physiol 1993; 264: G261-7.

31 Camilleri M, Brown ML, Malagelada JR. Relationship between impaired gastric emptying and abnormal gastrointestinal motility. Gastroenterology 1986; 91: 94-9.

32 Rao ASC, Lu R, Schulze-Delrieu K. Duodenum as an immediate brake to gastric outflow: a videofluoroscopic and manometric assessment. Gastroenterology 1996; 110: $740-7$.

33 Fraser R, Horowitz M, Maddox A, Dent J. Dual effects of cisapride on gastric emptying and antropyloroduodenal motility. Am f Physiol 1993; 264: G195-201.

34 Orihata M, Sarna SK. Contractile mechanisms of action of gastroprokinetic agents: cisapride, metoclopramide, and domperidone. Am 7 Physiol 1994; 266: G665-7. 